\title{
Retrospective analysis of a South African cardiovascular trial site's patient retention rates
}

This article was published in the following Dove Press journal:

Open Access Journal of Clinical Trials

25 November 2010

Number of times this article has been viewed

\author{
Lesley J Burgess \\ Nicole U Sulzer \\ TREAD Research/Cardiology Unit, \\ Department of Internal Medicine, \\ Tygerberg Hospital and University \\ of Stellenbosch, Parow, South Africa
}

Correspondence: Lesley J Burgess TREAD Research/Cardiology Unit, Department of Internal Medicine, Tygerberg Hospital and Stellenbosch University, Parow, South Africa

$\mathrm{Tel}+27219317825$

Fax +27219333597

Email lesley@treadresearch.com
Introduction: Patient dropouts negatively affect study cost and validity of study results.

Objectives: To investigate the attrition rate and reasons for patient discontinuations at a cardiovascular trial site in South Africa.

Methods: Studies conducted over the past 10 years were randomly selected and retrospectively examined for attrition rates and reasons for patient discontinuation.

Results: A total of 50 studies with a duration ranging from 3 to 45 months were examined. A total of 1386 patients were randomized. Of these, $88.9 \%$ completed all scheduled study visits, resulting in a mean $11.1 \%(n=154)$ attrition rate. Reasons for discontinuation included death (39.6\%), withdrawal of consent (33.1\%), adverse events $(22.7 \%)$, and relocation $(4.5 \%)$. There were no patients lost to follow-up.

Conclusion: The low attrition rate and absence of any patients lost to follow-up are the result of a dedicated retention plan in which each site staff member has a crucial role to play in keeping patients motivated and interested in participating in a clinical trial.

Keywords: clinical trials, lost to follow-up, attrition

\section{Introduction}

"Patient recruitment and retention in clinical trials is widely recognized as the leading bottleneck in the new drug development pipeline, and it is likely to remain an area of heightened concern."' Each patient enrolled in a clinical trial represents a significant amount of time, effort, and other resources. ${ }^{2}$ Patient dropouts and those lost to follow-up after recruitment negatively affect study duration, study cost, and the generalizing of study results, which may result in a delay in the drug's regulatory approval. ${ }^{2}$ High patient attrition rates also pose a risk to the interpretation and validity of the intended research findings. ${ }^{2-4}$ Furthermore, the cost to recruit a patient is significantly higher than to retain an existing patient in a clinical trial. ${ }^{5}$

Reported patient attrition rates range from $15 \%$ to $40 \%$ of enrolled subjects depending on the therapeutic area, investigational drug, inclusion/exclusion criteria, and patient characteristics. ${ }^{4,6}$ Disappointing statistics show that as many as $26 \%$ of patients drop out after providing consent. ${ }^{7,8}$ A recent study conducted at a Texas medical school retrospectively analyzed 541 randomly selected charts from clinical trials conducted between 2000 and $2006 .{ }^{9}$ This study reported an attrition rate of $52 \%$.

Common causes cited for patients' failure to complete a study often reflect issues related to competing life demands, logistical problems, demands of the study, and lack of motivation. ${ }^{2}$ The most commonly cited explanations for failure to complete the study are stress related and involve family care responsibilities and interference with work. ${ }^{10}$ Dropouts 
occur when patients' perceived time and effort invested in a study outweigh the perceived benefits of being in a study. ${ }^{10}$

\section{Objective}

The primary objective of this study was to investigate the attrition rate at our site and, secondly, to ascertain the reasons for patient discontinuation in order to implement corrective action in the future.

\section{Methodology}

This study was carried out by TREAD Research, a site-managed organization based within an academic hospital in the Western Cape, South Africa. Phase III cardiovascular studies that had been conducted over the past 10 years were randomly selected and retrospectively examined for attrition (dropout) rates. In this study, "attrition rate" is used to describe patient discontinuations for any reason, whereas "lost to follow-up" is used to describe a specific situation where the site has no idea as to the whereabouts and/or outcome of the patient, despite at least three documented attempts to contact them.

The attrition rates in this study were obtained from the local regulatory agency's 6-monthly progress report documents. In these documents, salient data pertaining to patient recruitment and retention are recorded by the investigator and submitted to the regulatory agency biannually. Investigators are required to indicate patients who withdraw prior to trial completion and specify the reason for their withdrawal as being either due to "lost to follow-up", "withdrawal of consent", "patient relocated", "worsening of condition", or "death". Data were entered into an Excel spreadsheet, and descriptive statistics were used to analyze the data in order to obtain a mean overall attrition rate as well as the percentage attrition per reason for discontinuation.

\section{Results}

The progress reports from 50 studies were examined. The duration of these studies ranged from a minimum of 3 months to a maximum of 45 months (3.75 years). A total of 1386 patients had been randomized to the 50 studies. Of these, 1232 patients $(88.9 \%)$ completed all their scheduled study visits as per protocol. There was thus a mean $11.1 \%(n=154)$ attrition rate for the 50 studies combined.

The various reasons for discontinuation are presented in Table 1. Death was responsible for $39.6 \%$ of subject discontinuations, withdrawal of consent for $33.1 \%$, adverse events (worsening of condition) for $22.7 \%$, and relocation for $4.5 \%$. There were no patients reported as being lost to follow-up.
Table I Reasons for discontinuation as a percentage of total number of patients who discontinued $(n=154)$ and as a percentage of total number of patients randomized $(n=1386)$

\begin{tabular}{llll}
\hline $\begin{array}{l}\text { Reason for } \\
\text { discontinuation }\end{array}$ & $\begin{array}{l}\text { Number of } \\
\text { patients (n) }\end{array}$ & $\begin{array}{l}\text { Percentage (\%) } \\
\text { of total subject } \\
\text { discontinuation } \\
(\mathbf{n}=\mathbf{1 5 4})\end{array}$ & $\begin{array}{l}\text { Percentage (\%) } \\
\text { of total } \\
\text { patients } \\
\text { randomized } \\
(\mathbf{n}=\mathbf{1 3 8 6})\end{array}$ \\
\hline $\begin{array}{l}\text { Death } \\
\begin{array}{l}\text { Withdrawal } \\
\text { of consent }\end{array}\end{array}$ & 61 & 39.6 & 4.4 \\
$\begin{array}{l}\text { Adverse events } \\
\text { (worsening of }\end{array}$ & 35 & 33.1 & 3.7 \\
condition) & & 22.7 & 2.5 \\
$\begin{array}{l}\text { Relocation } \\
\text { Lost to follow-up }\end{array}$ & 7 & & \\
\hline
\end{tabular}

\section{Discussion}

The main finding of this study was that the site's mean overall attrition rate was $11.1 \%$. Death was the main reason for discontinuation $(39.6 \%)$, followed by withdrawal of consent (33.1\%) and adverse events $(22.7 \%)$. A minor percentage of patients discontinued due to relocation (4.5\%). There were no patients reported as being lost to follow-up.

The results of this study showed a far better mean attrition rate than those previously reported in the literature, where dropout rates varied from $15 \%$ to $40 \%$., 6 However, it is important to state that discontinuation rates may vary depending on the therapeutic area, investigational drug, inclusion/exclusion criteria, and patient characteristics. $^{6}$

Death was the predominant reason for discontinuation $(39.6 \%)$, as reported by this analysis. Almost a quarter of discontinuations $(22.7 \%)$ were due to adverse events or worsening of condition. Both these findings can best be explained by the nature of the studies conducted at this site, namely cardiovascular endpoint-driven trials where the patient population is seriously ill.

A total of $33.1 \%$ of patients withdrew consent. This is similar to the $26 \%$ reported previously in the literature. ${ }^{7,8}$ A subset analysis of the 6-month withdrawal of consent showed that of the $33.1 \%$ who withdrew consent, $37.3 \%$ withdrew in the first month, and $23.7 \%$ in the second and third months. Thus, $61 \%$ of the informed consent withdrawals occurred in the first 3 months. This finding emphasizes the importance of the informed consent process and allowing patients the time to consider participation and time to ask questions so that they fully understand the scope of the study and their role. In addition, the informed consent form (ICF) itself plays a major role in the process, and it has been 
reported that the complexity of the ICF is a major barrier to comprehension for many patients. ${ }^{11,12}$

A small percentage (4.5\%) of discontinuations was due to patients relocating. This is an inevitable component in our local migratory society. Historically, South Africa's labor force has been a migratory one, moving from rural areas to cities in search of employment. Commendably, sponsors are often prepared to cover additional travel costs to ensure that patients remain in the study. Alternatively, patients are often able to continue their participation at sites closer to their new location. In this study, four of the seven patients who relocated were transferred to other sites within the country.

The most encouraging finding for our site was that no patients were lost to follow-up. It has been reported that as many as $80 \%$ of study failures are caused by the inability of research sites to find and enroll sufficient patients; these trials fail not because of the drug but because the trial's patient recruitment and retention goals were not achieved. ${ }^{13}$ A major pharma company recently analyzed the findings of a $\$ 2$ million retention program. ${ }^{13}$ The program retained close to 700 study subjects who had been at risk of dropping out and resulted in a three times greater performance rate. The monetary saving of retaining these patients exceeded $\$ 10$ million, not including the value of stronger data for analysis. $^{13}$

Many potential retention problems can be prevented or minimized before the patient is enrolled, and patient retention begins at the very first study visit. ${ }^{5}$ It is of utmost importance to understand the patient population. Understanding the various underlying motivators for each patient is the first step to ensuring that a patient's study expectations are met. ${ }^{3,5}$ A recent study investigated patients' motivations for participating in a trial. ${ }^{14}$ This study reported that access to medical care and making a contribution to scientific knowledge are two of the most common motivations for participation in cardiovascular clinical trials, and the role of remuneration is relatively unimportant. ${ }^{14}$

Furthermore, patient retention is a team effort, and all staff members of the site contribute to retaining patients on a trial. The principal investigator's involvement on a continual basis demonstrates the physician's interest in a patient's wellbeing and builds their trust in the research process. ${ }^{5}$ Additionally, there is no doubt that study coordinator turnover can affect patient retention, as continuous turnover impedes the ability of site staff to build lasting relationships with study patients. ${ }^{5}$
Some of the more common tips used at this site to improve retention include collecting as many contact details for the patient as possible, making visits special (by ensuring that there is a welcoming waiting room, that tea/coffee are provided, being supportive of patients and their condition), maintaining regular contact with patients, supplying them with a 24-hour contact number, and organizing extra visits if necessary. Retention gifts also help make patients feel valued. Unpublished data from this unit support the idea that retention gifts do not influence patients to participate in a clinical trial but do motivate their participation. It is also important to be aware of 'red flags', which may be early indicators of patients who are potentially losing interest in the study. These include missed visits, failure on the patient's behalf to return phone calls, complaints about site visits, and impatience during visits. ${ }^{5}$ It is crucial to remember that keeping patients motivated in a clinical trial is a continuous process. $^{3,5}$

\section{Conclusion}

Data consistently reveal that recruitment and retention issues have the greatest impact on clinical trial costs. ${ }^{13}$ Despite the importance of retention to study costs and data interpretation, it has only now started to receive specific attention in the clinical trial industry. The low attrition rate for this site and the absence of any patients who were lost to follow-up are the result of a dedicated and continuous retention plan in which each site staff member has a crucial role to play in keeping patients motivated and interested in participating in a clinical trial.

\section{Disclosure}

The authors report no conflicts of interest in this work.

\section{References}

1. Research and Markets' Resources Division. Challenges in Patient Recruitment for Clinical Trials: Overcoming the Bottleneck. 2005 Dec. Available from: http://www.researchandmarkets.com/ reportinfo.asp?report_id $=314806$. Accessed 2010 Oct 28.

2. Betz D, Betz D, Leahy D. Burden of Patient Dropouts and Patients Lost-To-Follow-Up on Clinical Studies. 2009 Jul. Available from: http:// lost-to-follow-up.com/patient-dropouts-patients-lost-to-follow-upclinical-studies/. Accessed 2010 Oct 28.

3. Olem D, Sharp KM, Johnson MO. Challenges with engaging participants in behavioural intervention research trials. Open Access $J$ Clin Trials. 2009;1:17-21.

4. Hewitt CE, Kumaravel B, Dumville JC, Torgerson DJ; for the Trial attrition study group. Assessing the impact of attrition in randomized controlled trials. J Clin Epidemiol. 2010;63(11):1264-1270.

5. Williams K, Hook-Seid N. Tried and True Techniques for Motivating and Retaining Patients in Clinical Trials. 2008 Apr. Available from: http:// mediciglobal.com/blog/tried_and_true_techniques_for_motivating_and_ retaining_patients_in_clinical/. Accessed 2010 Oct 28. 
6. Berger A, Neumark D. Enhancing recruitment and retention in randomised clinical management. Oncol Nurs Forum. 2007;34:e18.

7. Betz D. Addressing Clinical Trial recruitment and Patient Retention Issues Imposed by HIPAA Step by Step. 2008. Available from: http:// lost-to-follow-up.com/patient-recruitment-retention-hipaa/. Accessed 2010 Oct 28.

8. Avitabile D. Marketing strategies for clinical trial recruitment and patient retention: behind every new medicine are the volunteers who take. Entrepreneur Magazine. 2006 Dec. Available from: http://www. entrepreneur.com/tradejournals/article/160641723.html. Accessed 2010 Oct 28.

9. Sangi-Haghpeykar H, Meddaugh HM, Liu H, Grino P. Attrition and retention in clinical trials by ethnic origin. Contemp Clin Trials. 2009; 30(6):499-503.

10. Janson S, Alioto M, Boushy H. Attrition and retention of ethnically diverse subjects in a multicenter randomised controlled research trial. Control Clin Trials. 2001;22:236-243.
11. South African Department of Health. Guidelines for Good Practice in the Conduct of Clinical Trials with Human Participants in South Africa. 2nd ed. Pretoria: Department of Health; 2006.

12. Terblanche M, Burgess LJ. Examining the readability of patient informed consent forms. Open Access J Clin Trials. 2010;2:1-6.

13. Moench E. The Business of Recruitment. Applied Clinical Trials. 2009 Mar. Available from: http://appliedclinicaltrialsonline.findpharma.com/ appliedclinicaltrials/data/articlestandard/appliedclinicaltrials/122009/5 87878/article.pdf. Accessed 2010 Oct 28.

14. Burgess LJ, Sulzer NU, Hoosain F, et al. Patients' motivations for participating in cardiovascular clinical trials: a local perspective. Cardiovasc J Afr. 2009;20:220-223.

\section{Publish your work in this journal}

The Open Access Journal of Clinical Trials is an international, peerreviewed, open access journal publishing original research, reports, editorials, reviews and commentaries on all aspects of clinical trial design, management, legal, ethical and regulatory issues, case record form design, data collection, quality assurance and data auditing methodologies. The manuscript management system is completely online and includes a very quick and fair peer-review system, which is all easy to use. Visit http://www.dovepress.com/testimonials.php to read real quotes from published authors. 